\title{
Study of Excavation Stability and Treatment Measures of the Side Slope of Anti-Dip Bedding Highway
}

\author{
Qian Shen , Liu Liu , Jinxiu Yuan \\ Department of Civil Engineering, Hebei Jiaotong Vocational and Technical College, Shijiazhuang Hebei China 050091
}

\begin{abstract}
In order to improve the slope safety of the side slope of anti-dip bedding highway, this paper analyzes the stability of the excavation by using the finite difference numerical simulation technique. The development process of the disaster under the three excavation conditions and the whole process of the slip surface of the anti dip bedding rock slope are revealed; The method of determining the potential slip surface is introduced, that is to say, the slope is unstable and slip by reducing the material parameters of the slope, and then the position of the slip surface is judged by the difference of the displacement value. The research results have important significance for understanding the development mechanism of slope disaster and adopting corresponding engineering measures for different stages of slope.
\end{abstract}

\section{Introduction}

The slope is a dome with a certain slope and it is made to ensure the stability of the roadbed on both sides of the roadbed [1]. In recent years, with the increasing mileage of highway, the stability of slope excavation in mountainous area of highway is becoming more and more serious, which brings great losses to people's travel and life and property. Therefore, it is necessary to study the stability of anti -dip highway slope excavation.

At present, some experts have done some researches on the stability of slope excavation. The main research works are as follows: the deformation and failure mechanism of anti dip bedding slope during excavation and unloading is studied [2-3]. The stability of bedding rock slope during excavation is studied [4-5]. The application of strength reduction method in slope stability analysis is studied [6-8]. The above studies have been carried out on the stability of anti dip and bedding slopes and the determination methods of slip surfaces. However, the stability and slip surface determination method of the side slope of anti-dip bedding highway are not studied. Therefore, This paper mainly study the stability of the slope during the excavation of the side slope of anti-dip bedding highway by using the inite difference numerical simulation technique. The research results can provide reference for excavation stability study of similar projects.

\section{Analytical Model}

\subsection{Geological conditions of slope}

The strata in the slope area are mainly purple red mudstone of the lower three series. The slope area is inclined anticline structure, the axis of anticline is inclined to 45 degrees with the slope, and the rock stratum is inverted, and the changes of attitude is larger.

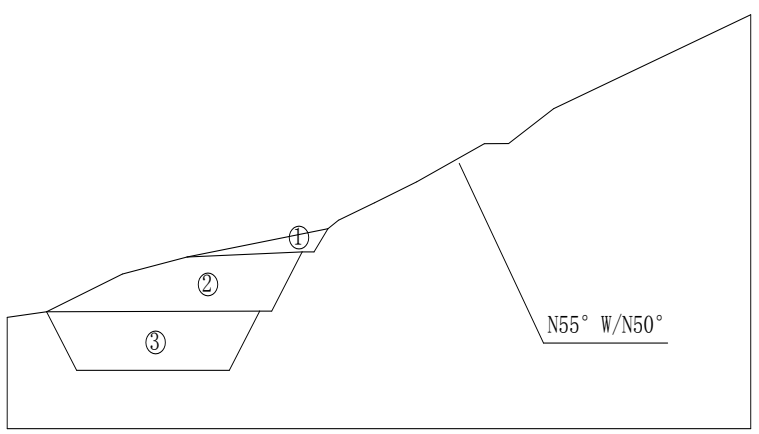

Fig. 1: Generalized geological model

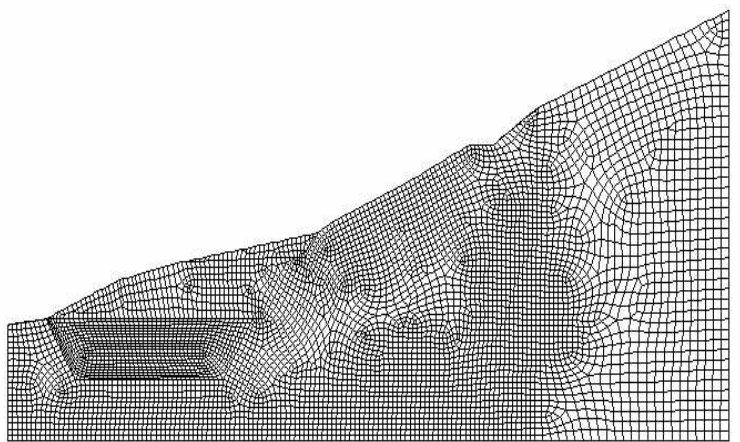

Fig. 2: Discrete calculation model 


\subsection{Computational model}

The horizontal distance of the model is $91.71 \mathrm{~m}$, the vertical height is $45.92 \mathrm{~m}$, and the vertical width is $1 \mathrm{~m}$. The effect of the lateral pressure on the right boundary is triangular distribution, the bottom boundary is constrained by vertical displacement, the left boundary is constrained by horizontal displacement, and the lateral boundary is constrained by horizontal displacement in the direction of Y. The slope rock mass is layered rock mass, and the intraformational joint controls the deformation of landslide body. Ubiquitous-joint model is used in the calculation. The calculation model is shown in figure 2 .

Table 1: Calculation steps

\begin{tabular}{c|c}
\hline Step & Study object \\
\hline 1 & Excavation ( (1) ) \\
\hline 2 & Excavation ( (2) ) \\
\hline 3 & $\begin{array}{c}\text { The potential slip surface is determined } \\
\text { after step 2 }\end{array}$ \\
\hline 4 & Excavation ( (3) ) \\
\hline
\end{tabular}

\subsection{Calculation parameters}

The calculation parameters of slope are shown in table 2 .

\section{Calculation results analysis}

\subsection{First excavation}

Table 2: The calculation parameters

\begin{tabular}{c|c|c|c|c|c|c}
\hline $\begin{array}{c}\text { Slope } \\
\text { structure }\end{array}$ & $\begin{array}{c}E \\
(\mathrm{MPa})\end{array}$ & $\mu$ & $\begin{array}{c}\gamma \\
\left(\mathrm{KN} / \mathrm{m}^{3}\right)\end{array}$ & $\begin{array}{c}\mathrm{C} \\
(\mathrm{KPa})\end{array}$ & $\begin{array}{c}\varphi \\
\left({ }^{\circ}\right)\end{array}$ & $\begin{array}{c}T \\
(\mathrm{KPa})\end{array}$ \\
\hline Rock & 11000 & 0.28 & 22 & 300 & 35 & 300 \\
\hline Joint & 11000 & 0.28 & 22 & 40 & 28 & 40 \\
\hline
\end{tabular}

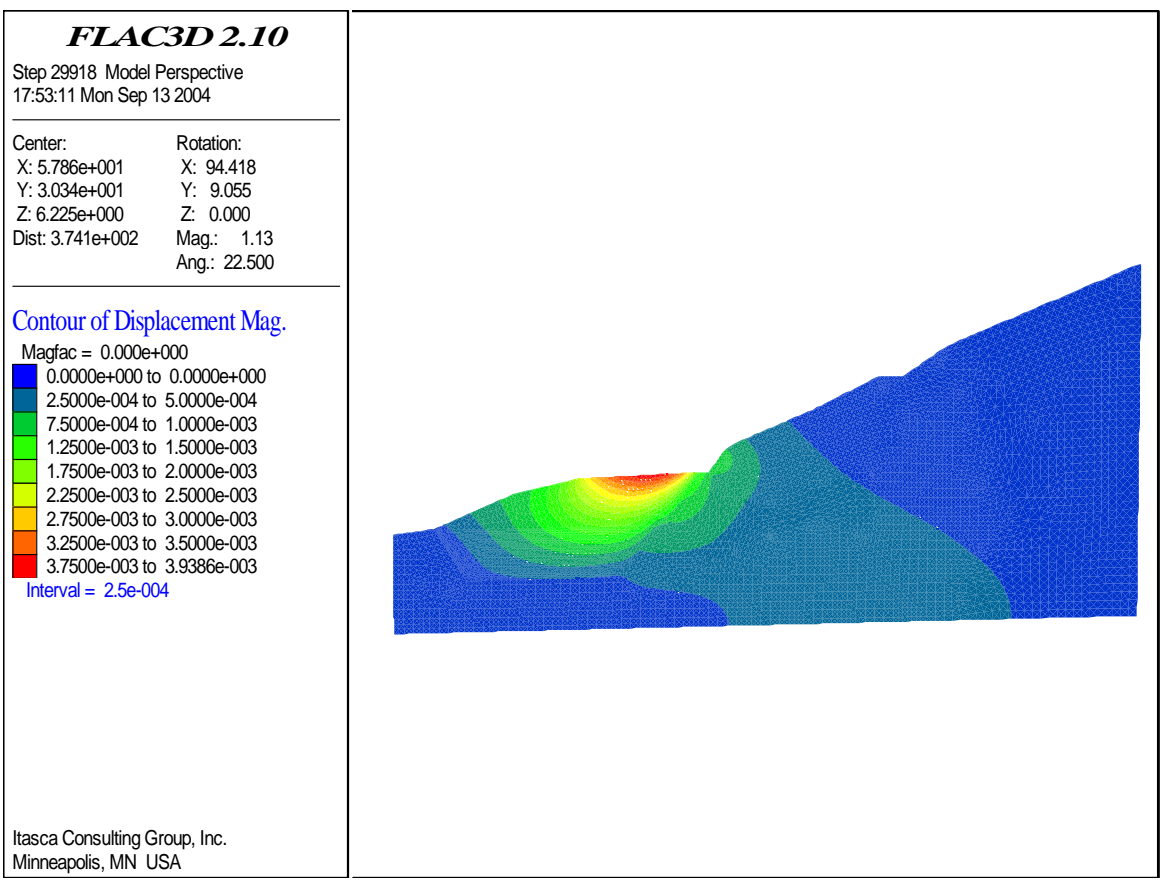

Fig. 3: Displacement (step 1) 

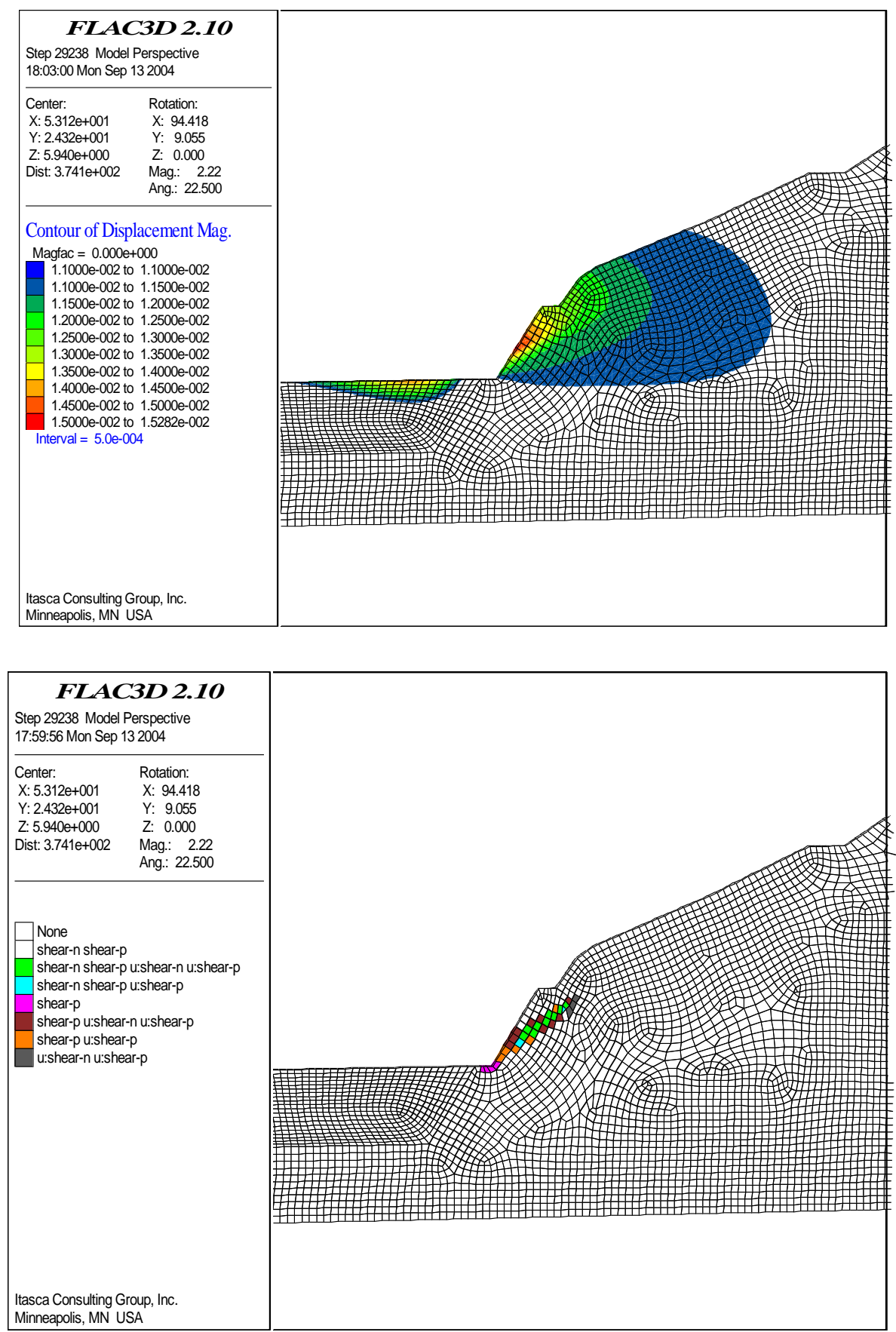

Fig. 4: The calculation results of step 2

To sum up, the plastic zone in the slope is limited to a limited range, and the deformation zone shown in Figure 4 is mainly due to the adjustment of the elastic stress caused by excavation unloading, so the displacement is not large. Because the slope is an anti dip rock stratum, and it is beneficial to the stability of slope. The artificial slope stability of the second excavation is better, only local plastic deformation, no overall slip.

\subsection{Determination of potential slip surface after second excavation}

In order to further analyze the stability of slope after the first excavation and the second excavation, and to find the potential slip surface of slope under the influence of various external factors. It reduces the rock and soil parameters of slope are reduced.

In the calculation, the smaller reduction factor is used to test the slope, and the slope slip surface does not form under a certain ninety percent off reduction factor. If the slope slip surface is not formed under a certain reduction factor, the calculation will be continued by increasing the reduction factor, and until a uniform complete slide surface appears.

\subsection{Determination of potential slip surface}

This paper mainly studied the process of plastic damage to the slip surface. When the reduction factor $\mathrm{K}$ is 2.5 , a uniform slip surface is formed in the slope. The calculation results are shown in Figure 5. 


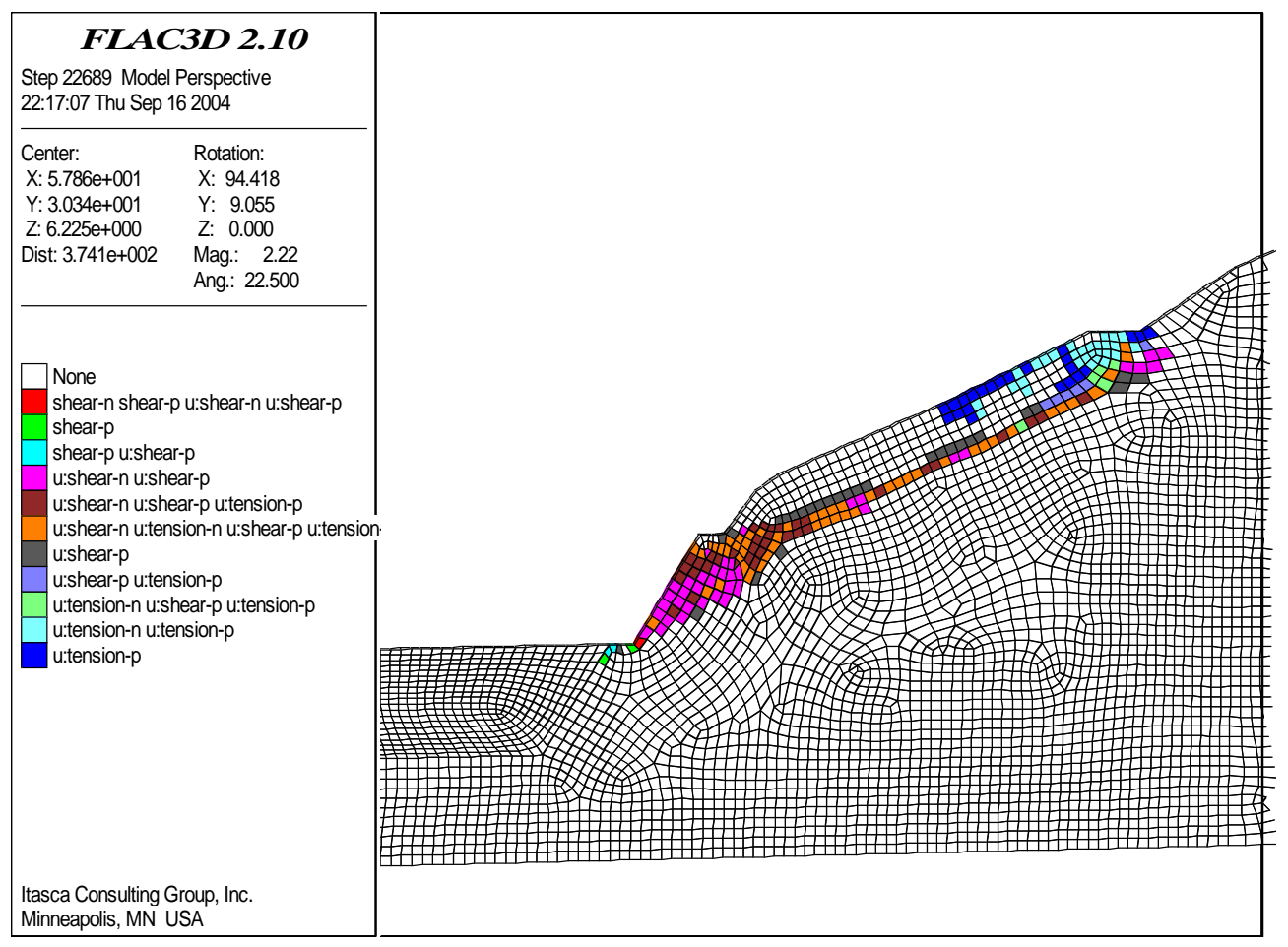

(a) The plastic zone at the beginning of the calculation

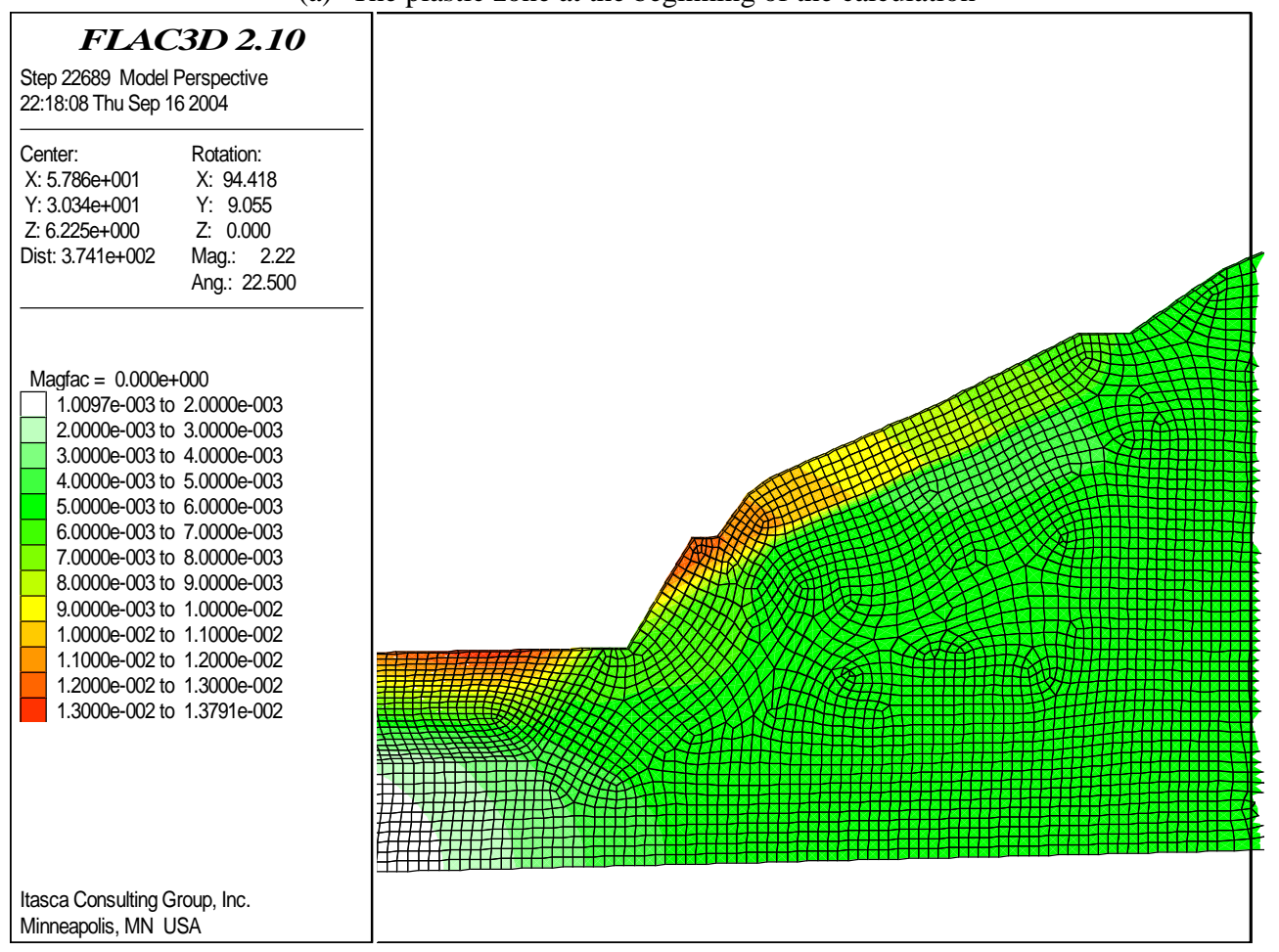

(b) The displacement at the beginning of calculation 


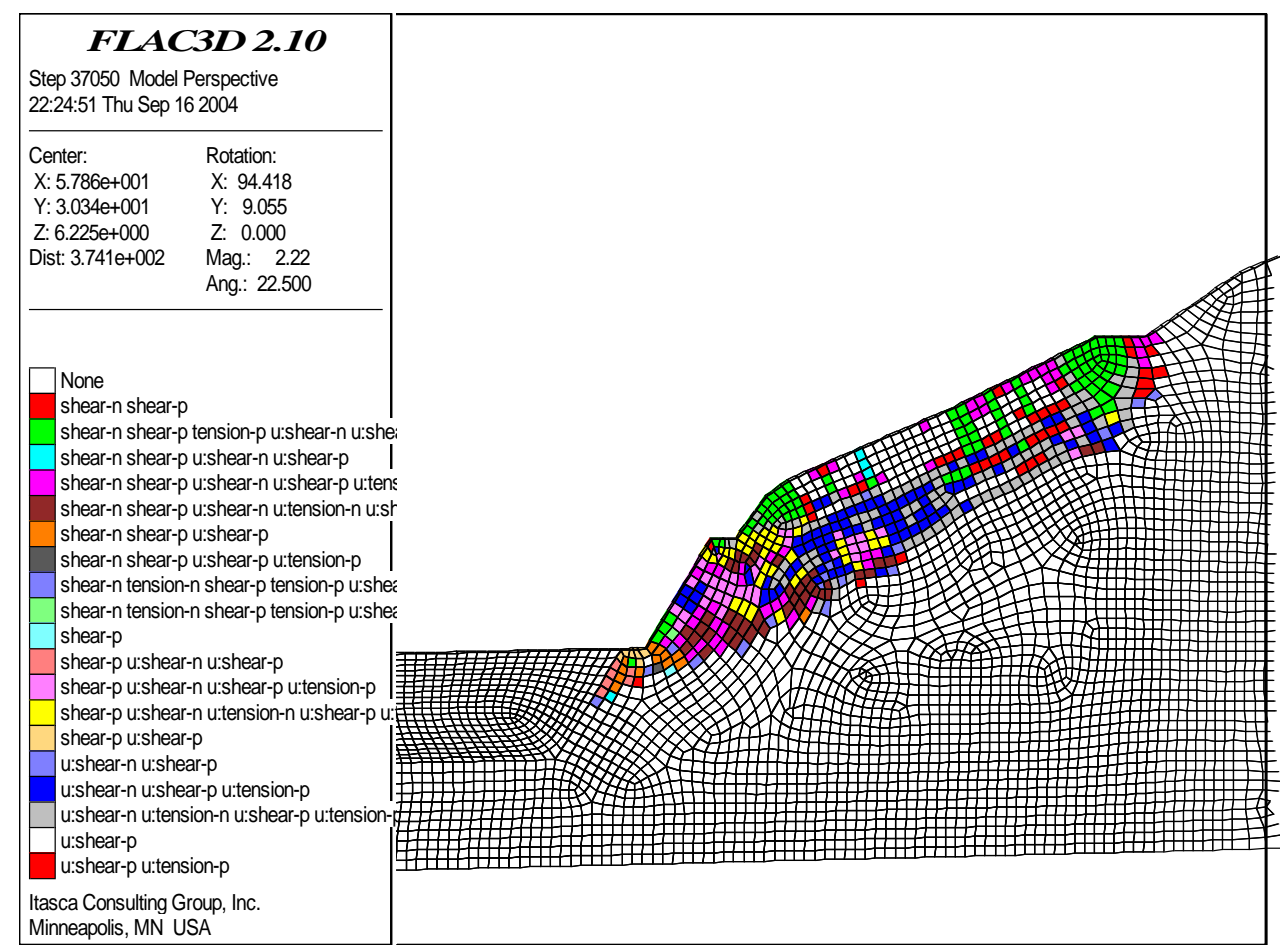

(c) The plastic zone at the end of the calculation

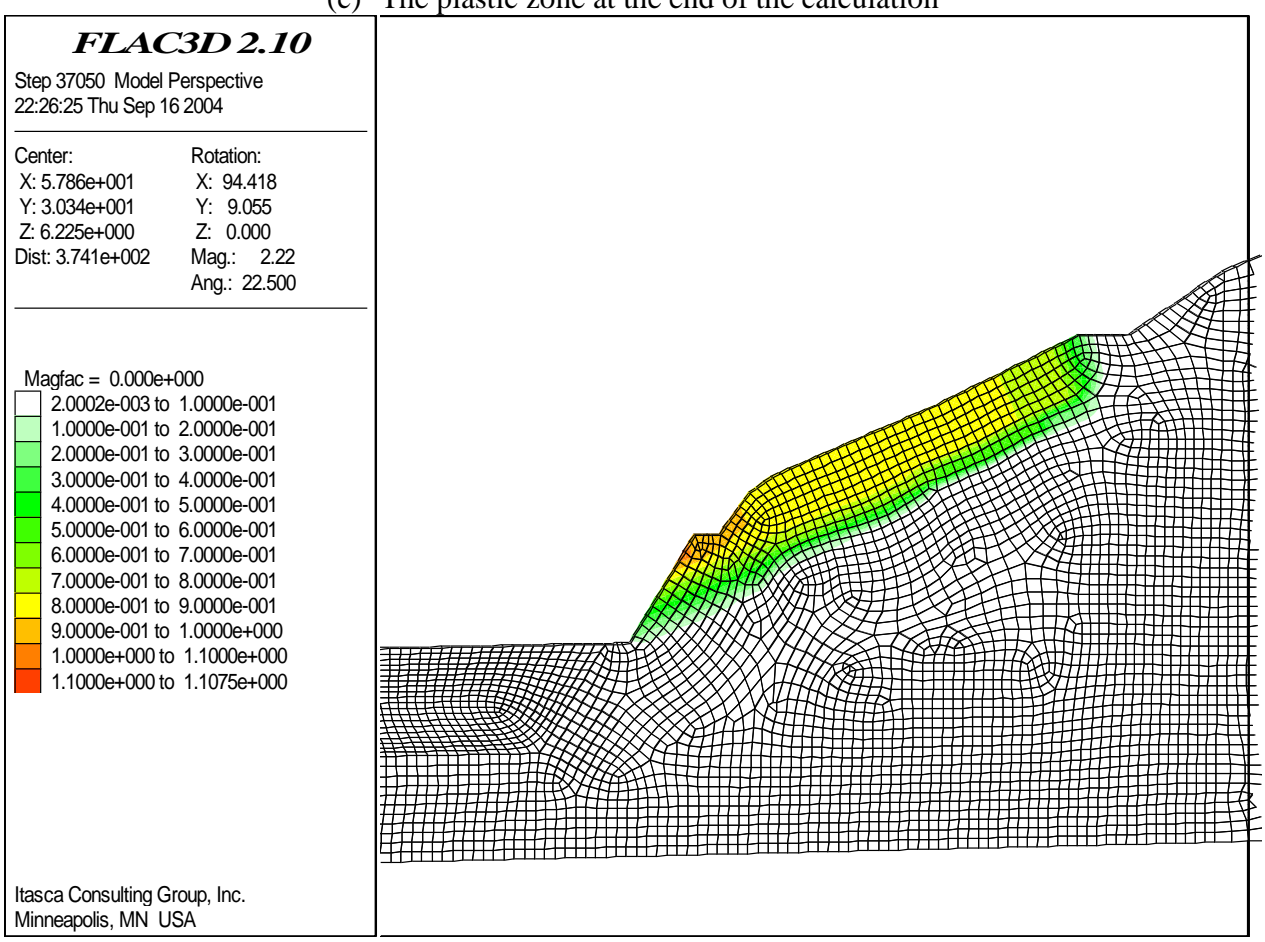

(d) The displacement zone at the end of the calculation

Fig. 5: The calculation results of step 3

As shown in Fig. 5, when the calculation starts, the plastic unit in the slope and the plastic unit on the slope have been integrated, and the plastic influence range of the slope deformation caused by the excavation scope has been preliminarily revealed. At this point, the displacement of the slip surface can not be determined from the displacement of the slope, and the displacement vector contour is shown in Figure 5 (b). The maximum displacement in the plastic zone of the slope is almost the same as the maximum displacement at the excavation horizontal plane, and the maximum value is $13.791 \mathrm{~mm}$. From the displacement in the plastic zone, the upper displacement on the leading edge of the slope is greater than the displacement at the bottom, and the position of the displacement interface have seen indistinctly, but the displacements interface between the front and back is not clear. By contrast (a) and (c), it can be seen that after the formation of the slip surface, the plastic zone in the slope has little change, and there is almost no expansion before and after the slip surface, but only the depth increases more. 


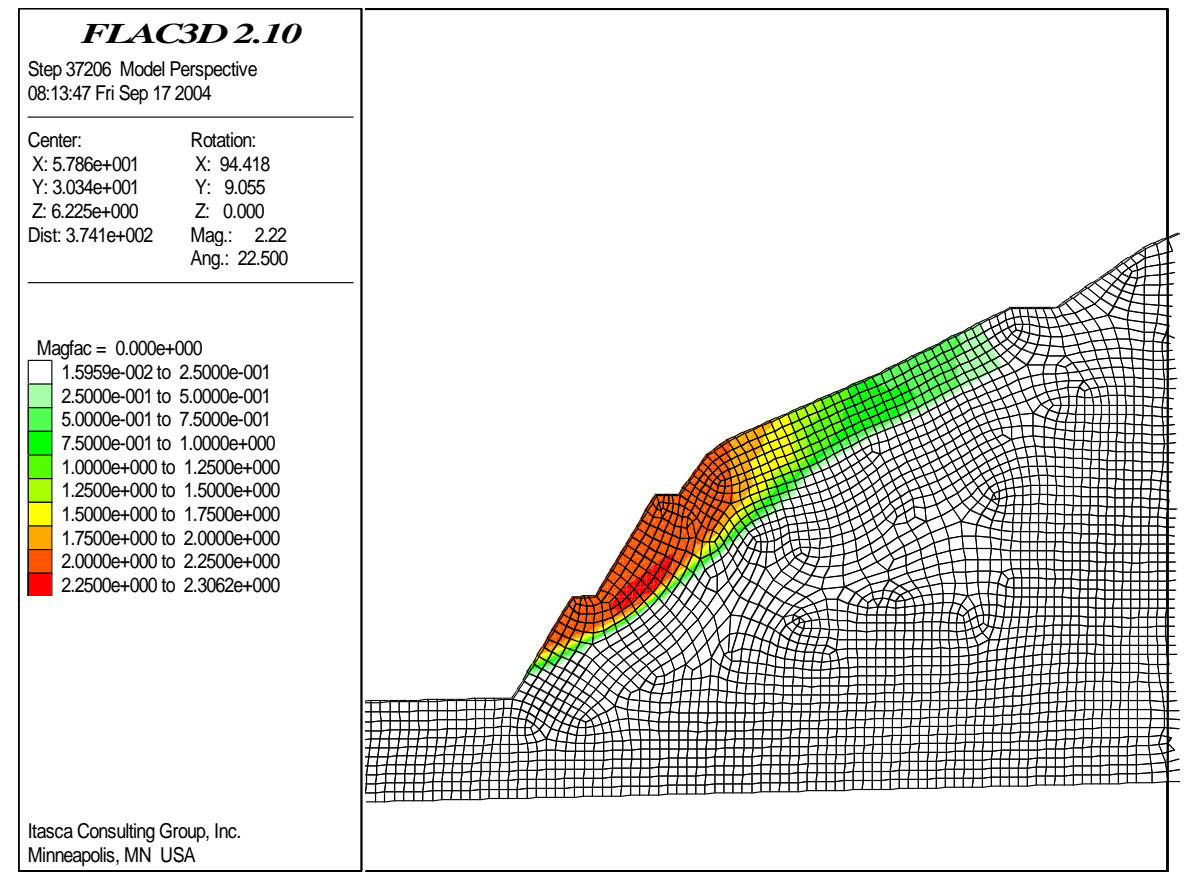

Fig. 6: The calculation results of step 4

At the end of the computation, slip surface has been formed, The slide surface begins to extend obliquely from the foot to the top of the slope. The slip surface of the trailing edge becomes basically vertical, and the thickness of the sliding body is almost the same.

\subsection{Third excavation}

The calculation results after the third excavation are shown in figure 6.

As shown in Fig. 6, after the calculation, the slip surface of the slope revealed by the displacement is very clear, and the displacement of each point in the sliding body is more than $0.25 \mathrm{~m}$, and the boundary of the slip surface is very clear. The result of stress adjustment of the slope after excavation is that a landslide is formed in the slope. According to the different displacement values in the landslide, the landslide body is divided into two grades, the former landslide displacement is larger, and the latter landslide displacement is small. The maximum displacement of the sliding body is $2.306 \mathrm{~m}$, and the overall displacement of the front sliding body is near the maximum, and the displacement of the back sliding body is more than $0.25 \mathrm{~m}$, and the displacement change is obvious.

\section{Treatment measures}

The stability of the slope is affected by geological conditions, rainfall, excavation and other factors. Therefore, under different influence factors, for a specific slope, choosing the reasonable and effective engineering and technical measures is the key to achieve the desired goal of slope treatment.

(1)At present, the main measures of slope treatment areas follows: Anti sliding retaining wall, anchor and prestressed anchor cable, anti slide pile, prestressed anchor pile, etc.
(2)According to the stability of the anti-dip bedding slope, the stability of slope decreases during excavation. The toe of the slope stability is the worst, and it is the most dangerous part of the slope. Therefore, combined with the failure characteristics of the slope, in practical engineering, the anti slide pile, anti slide pile and prestressed anchor rope can be used to reinforce the slope.

\section{Conclusion}

(1)The slope stability of the first excavation and the second excavation is better, it produces only local deformation at the foot of the slope, and no overall slip. After the third excavation, a plastic zone is formed in the slope, and the slope gradually loses its stability and forms a landslide.

(2)The development process of the disaster under the three excavation condition reveals the whole process of the whole process of the formation of the slip surface of the anti-dip bedding slope, and the specific position of slip surface is determined. After the slip surface is formed, the plastic zone in the slope does not continue to develop, but the displacement continues to increase.

(3)In practical engineering, it is suggested to use the method of anti slide pile, anti slide pile and prestressed anchor cable.

\section{Acknowledgements}

This work was financially supported by the Natural Science Foundation of HebeiProvince(No.E201619002), Hebei Talent Training Fund(A201500116), Key R \& D Project of Hebei Province(172776471).

\section{References}

1. JIANG Deyi, WANG Guodong. Engineering 
geological classification of highway engineering Slope, Journal of Chongqing University(Natural Science Edition), Vol.26, No.11, pp. 113-116, 2003.

2. YANG Xianwen. Stability analysis of excavation slope and study on deformation and failure mechanism, Railway Construction Technology, No.02, pp. $100-103+112,2015$

3. LENG Xianlun, SHENG Qian, LIAO Hongjian, et al. Study on deformation and failure mechanism of high slope excavation in anti-dumping, Chinese Journal of Rock Mechanics and Engineering, Vol.23, No.S1, pp. 4468-4472, 2004.

4. FENG Jun, ZHOU Depei, Li Anhong. Research on stability of rock bedded slopes, Chinese Journal of Rock Mechanics and Engineering, Vol.24, No.9, pp. 1474-1478, 2005.
5. YU Fei, CHEN Shanxiong, YU Heping. Numerical simulation study on progressive destruction and failure mechanism of bedding rock slopes, Rock and Soil Mechanics, Vol.26, No.2, pp. 36-40, 2005.

6. LIU Xiaodong, ZHANG Zhongping, SUN Shuwei. Applicat-ion of strength reduction method in high-steep rock slope engineering, Railway Engineering, Vol.26, No.7, pp. 97-99, 2012.

7. CHENG Canyu, LUO FUrong, QI Chengzhi, et al. Comparative analysis of slope stability by strength reduction method, Rock and Soil Mechanics, Vol.33 No, 11, pp. 3472-3478, 2012.

8. WU Yingxiang, LIU Dongsheng, SONG Qianghui, et al. Reliability analysis of slope dynamic stability based on strength reduction method, Rock and Soil Mechanics, Vol.34, No.07, pp. 2084-2090, 2013. 